(respectively PGA and PhGA) were rated on a 0-10 numeric scale, every 6 months during 2 years then at 3 years. Only patients with all data available for PGA and PhGA for each of the 6 visits were included. Repeated discordance was defined as an absolute difference $|\mathrm{PGA}-\mathrm{PhGA}| \geq 3 / 10$ for at least 3 of the 6 visits (i.e., at least half of the visits). Univariable and multivariable logistic models were used to determine if repeated discordance was associated at the 3 years timepoint, with prescription of TNFi, functional incapacity defined as $\mathrm{HAQ}>0.5$, and remission defined as ASDAS-CRP $<1.3$.

Results: Of 401 patients, mean age $34.6 \pm 8.7$ years, mean symptoms duration $17.8 \pm 10.7$ months, $219(54.6 \%)$ were female and mean ASDAS-CRP at baseline $2.7 \pm 1.0$. At 3 years $140(34.9 \%)$ patients had been prescribed a TNFi, 172 (43.2\%) had $\mathrm{HAQ}>0.5$ and $89(25.1 \%)$ were in remission. Over the 6 visits, mean PGA was higher than mean PhGA with a mean absolute difference of $0.8 \pm 2.2$ points. Discordance concerned $110(27.4 \%)$ patients at baseline and repeated discordance concerned $92(22.9 \%)$ patients. In multivariable logistic regression, after adjusting on the others significant factors (which included MRI sacro-ilitis, HLA-B27 and ASDAS-CRP at baseline), repeated discordance was associated with more functional incapacity $(61 \%$ vs $38 \%$, odds ratio, OR $2.85[95 \% \mathrm{Cl}$ $1.49-5.62]$ ) and less remission (10\% vs $30 \%$, OR 0.38 [0.15-0.85]) but not more TNFi use (34\% vs $35 \%, 1.39$ [0.78-2.54] $\mathrm{p}=0.27)$.

Conclusions: In early axSpA, repeated discordance concerned $22.9 \%$ of patients confirming the frequency of this situation. Repeated discordance was associated with worse outcomes at 3 years, even after adjustment of other factors including baseline ASDAS, indicating for the first time that discordance may indeed reflect an unsatisfactory management of medical care leading to worse outcomes. Future studies should concentrate on understanding the reasons of patient-physician discordance for disease activity in axSpA.

References:

[1] Desthieux C, Molto A, Granger B, Saraux A, Fautrel B, Gossec L. Patientphysician discordance in global assessment in early spondyloarthritis and its change over time: the DESIR cohort. Ann Rheum Dis. 2015 Oct. 22.

[2] Dougados M, Etcheto A, Molto A, Alonso S, Bouvet S, Daurès J-P, et al. Clinical presentation of patients suffering from recent onset chronic inflammatory back pain suggestive of spondyloarthritis: The DESIR cohort. Joint Bone Spine. 2015 Oct:82(5):345-51.

Acknowledgements: The DESIR cohort is financially supported by unrestricted grants from the French Society of Rheumatology and Pfizer France. These analyses were supported through an unrestricted academic grant from Pfizer France.

Disclosure of Interest: None declared

DOI: 10.1136/annrheumdis-2017-eular.4417

\section{FRI0474 DOES AXIAL SPONDYLOARTHRITIS PHENOTYPE CORRELATE WITH IMAGING MORPHOTYPE?}

$\underline{\text { X. Baraliakos }}{ }^{1}$, A. Szumski ${ }^{2}$, H.E. Jones ${ }^{3}$, L. Gensler ${ }^{4} .{ }^{1}$ Ruhr University, Bochum, Germany; ${ }^{2}$ inVentiv Health, Princeton; ${ }^{3}$ Pfizer, Collegeville; ${ }^{4}$ University of California, San Francisco, United States

Background: Traditionally, radiographic imaging was used to describe morphological differences between various types of axial SpA (axSpA). The advent of MRI has advanced understanding of disease, enabled earlier diagnosis and visualization of structural changes, and facilitated the identification of non-radiographic axial SpA (nr-axSpA). The magnitude of the pathologic changes in the axial skeleton is used to quantify inflammatory and structural outcomes of clinical trials and treatment of patients with axSpA.

Objectives: To examine the MRI morphology of sacroilitis (SI) and vertebral corner lesions in patients with primary $\left(1^{\circ}\right.$, no psoriasis) and secondary $\left(2^{\circ}\right.$, with psoriasis) axSpA.

Methods: This posthoc analysis was performed on data from patients with axSpA enrolled in the EMBARK trial (NCT01258738). Only patients with baseline MRI lesions were included. Symmetric and asymmetric SI, structural lesions, and corner inflammatory lesions were analyzed in $1^{\circ}$ axSpA vs $2^{\circ}$ axSpA patients. Data were analyzed using one-way analysis of variance for continuous parameters, chi-square tests, or Fisher's exact tests for categorical parameters. Results: The baseline demographics and disease characteristics between the 122 patients with $1^{\circ}$ axSpA and 19 with $2^{\circ}$ axSpA were similar. Asymmetric sacroiliitis was seen in significantly fewer $1^{\circ}(43 \%)$ vs $2^{\circ}(68 \%)$ axSpA patients. There were no differences in mean SpondyloArthritis Research Consortium of
Canada (SPARCC) scores between $1^{\circ}$ and $2^{\circ}$ axSpA for any of the $4 \mathrm{SI}$ joint (SIJ) quadrants. However, the lower iliac quadrants had the highest SPARCC SIJ score and the upper iliac quadrants had the lowest SPARCC SIJ scores. When analyzing the 4 spine quadrants (lower/upper anterior and lower/upper posterior), $1^{\circ}$ patients had higher total SPARCC spine scores than $2^{\circ}$ patients for all 4 quadrants at baseline. Collapsing the 4 quadrants shows that $1^{\circ}$ axSpA patients had higher SPARCC MRI of the entire spine (23 discovertebral units [DVU]; mean $=5.7$ ) compared with $2^{\circ}$ axSpA patients (mean $=2.7$ ).

Conclusions: We found $1^{\circ} \mathrm{axSpA}$ patients had more symmetric sacroilitis and extensive spinal bone marrow edema compared with $2^{\circ}$ axSpA patients. In addition, women appeared to have more asymmetric sacroiliitis. These data may help physicians accurately diagnose patients and decide best treatment options.

Disclosure of Interest: X. Baraliakos: None declared, A. Szumski Employee of: inVentiv, H. Jones Shareholder of: Pfizer, Employee of: Pfizer, L. Gensler Consultant for: AbbVie, Janssen, Novartis, Pfizer

DOI: 10.1136/annrheumdis-2017-eular.3681

\section{FRI0475 ANTI-CD74 ANTIBODIES AS DIAGNOSTIC BIOMARKER FOR EARLY AXIAL SPONDYLOARTHRITIS: DATA FROM THE SPONDYLOARTHRITIS CAUGHT EARLY (SPACE) COHORT STUDY}

J.J. de Winter ${ }^{1}$, M.G. van de Sande ${ }^{1}$, N. Baerlecken ${ }^{2}$, I.J. Berg ${ }^{3}$, R. Ramonda ${ }^{4}$, D. van der Heijde ${ }^{5}$, F.A. van Gaalen 5 , T. Witte ${ }^{2}$, D.L. Baeten ${ }^{1} .{ }^{1}$ AMC,

Amsterdam, Netherlands: ${ }^{2} \mathrm{MHH}$, Hannover, Germany; ${ }^{3}$ Diakonhjemmet Hospital, Oslo, Norway; ${ }^{4}$ UniPD, Padua, Italy; ${ }^{5}$ LUMC, Leiden, Netherlands

Background: Diagnosis of axSpA is often delayed with 5-10 years. A robust biological disease marker is lacking and could decrease the current diagnostic delay. Two studies showed that serum anti-CD74 $\lg G$ antibodies are increased in $\mathrm{SpA}^{1,2}$

Objectives: To explore the value of anti-CD74 antibodies as diagnostic biomarker for axSpA in patients with early, chronic back pain

Methods: We tested the prevalence of anti-CD74 $\operatorname{lgG}$ and $\lg A$ antibodies in patients from the SPondyloArthritis Caught Early (SPACE) cohort by enzymelinked immunosorbent assay (ELISA). Patients from the SPACE cohort have chronic back pain for $>3$ months and $\leq 2$ years with an onset $<45$ years.

Results: We included 560 patients of the SPACE cohort, of whom 274 patients were diagnosed with axSpA by a rheumatologist at baseline. Anti-CD74 lgG levels did not differ between patients with and without axSpA ( $p=0.152$, Table 1). Median anti-CD74 IgA levels (tested with either casein or BSA as a blocking buffer) were higher in patients with axSpA (both $p<0.0001$ ). Despite these differences at the group level, the diagnostic value of the anti-CD74 IgA antibodies was limited as shown by ROC analysis. The optimal cut off according to ROC analysis was an optical density (OD) of 0.875 , providing a sensitivity of $38.3 \%$ and a specificity of $77.6 \%$. In line with previous reports, further analysis revealed that total $\operatorname{Ig} A$ levels were elevated in early axSpA patients vs. non-SpA early back pain patients $(p=0.008)$. When correcting the level of anti-CD74 IgA for the level of total $\lg A$, the differentiating capacity of anti-CD74 disappeared for casein but remained intact for BSA (casein: $p=0.731, B S A: p=0.038$ ). Additional analyses using the ASAS classification criteria rather than a clinical diagnosis of axSpA, a strict combination of clinical diagnosis and ASAS classification criteria (excluding patients fulfilling the ASAS axSpA criteria without a clinical diagnosis and vice versa) (Table 1) and using the clinical diagnosis at 1 year of follow-up yielded similar results.

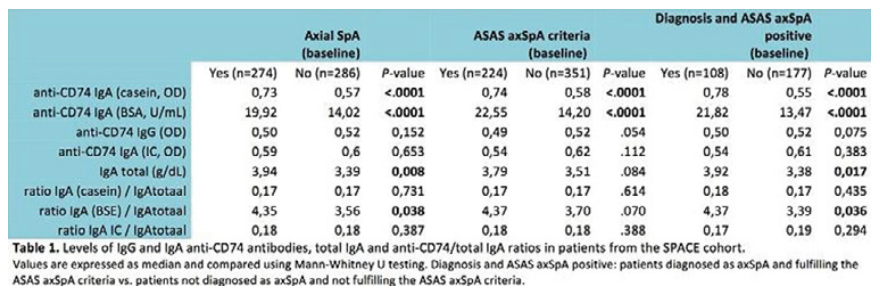

Conclusions: Serum anti-CD74 lgA antibody levels, but not serum anti-CD74 IgG levels, are elevated in patients with axSpA versus non-SpA with back pain of $<2$ years duration. However, ROC analyses revealed that these numerical differences are of limited diagnostic value in these patients with early back pain.

Abstract FRI0474 - Table

\begin{tabular}{|c|c|c|c|c|c|c|c|c|}
\hline \multirow[t]{2}{*}{ Parameter } & \multirow[t]{2}{*}{ Total $(n=141)$} & \multicolumn{3}{|c|}{$1^{\circ} \mathrm{axSpA}$ with } & \multicolumn{3}{|c|}{$2^{\circ}$ axSpA with } & \multirow[t]{2}{*}{$P$ value } \\
\hline & & Symmetric SI $(n=63)$ & Asymmetric $\mathrm{SI}(\mathrm{n}=52)$ & Non-SI $(n=7)$ & Symmetric SI $(n=4)$ & Asymmetric $\mathrm{SI}(\mathrm{n}=13)$ & Non-SI $(n=2)$ & \\
\hline Age, y & $32.1(7.4)$ & $30.9(6.8)$ & $32.5(7.8)$ & $35.3(7.3)$ & $29.3(7.9)$ & $33.5(6.2)$ & $47.0(2.8)$ & 0.2132 \\
\hline Male, $\mathrm{n}(\%)$ & $92(65.3)$ & $46(73.0)$ & 27 (51.9) & $4(57.1)$ & $4(100)$ & $9(69.2)$ & $2(100)$ & 0.0896 \\
\hline Symptom duration, y & $2.6(1.9)$ & $2.4(2.2)$ & $2.6(1.5)$ & $2.7(1.6)$ & $1.8(1.5)$ & $3.2(1.6)$ & $2.9(1.6)$ & 0.2944 \\
\hline SPARCC MRI SIJ score & $10.5(9.9)$ & $15.9(10.4)$ & $5.4(5.1)$ & $2.1(0.2)$ & $27.5(10.2)$ & $5.9(4.1)$ & $2.5(0.7)$ & 0.0007 \\
\hline Left SPARCC SIJ & $5.2(6.0)$ & $7.9(6.1)$ & $3.1(5.3)$ & $0.8(0.3)$ & $10.4(7.4)$ & $1.8(2.1)$ & $1.3(0.4)$ & 0.0004 \\
\hline Right SPARCC SIJ & $5.4(6.2)$ & $8.0(7.0)$ & $2.3(2.5)$ & $1.4(0.2)$ & $17.1(6.3)$ & $4.0(5.0)$ & $1.3(0.4)$ & 0.0542 \\
\hline SPARCC MRI 6 DVU spinal score & $4.7(6.8)$ & $6.4(8.5)$ & $3.8(5.5)$ & $2.4(2.1)$ & $1.6(3.3)$ & $2.6(3.4)$ & $0.8(1.1)$ & 0.0133 \\
\hline SPARCC MRI 23 DVU spinal score & $5.3(9.3)$ & $7.5(12.2)$ & $4.0(6.0)$ & $2.4(2.1)$ & $1.6(3.3)$ & $3.4(5.3)$ & $0.8(1.1)$ & 0.0335 \\
\hline Fat metaplasia & $0.5(1.6)$ & $0.3(0.9)$ & $0.9(2.5)$ & $0(0)$ & $0.3(0.5)$ & $0.7(1.1)$ & $0(0)$ & 0.6805 \\
\hline Erosions & $2.6(3.5)$ & $4.2(4.0)$ & $1.1(2.0)$ & $0.3(0.4)$ & $3.1(1.8)$ & $1.0(1.9)$ & $0(0)$ & 0.0002 \\
\hline
\end{tabular}

